\title{
Perceptions of storm surges in north Queensland
}

Peer Reviewed

\section{Kristy Livock ${ }^{1}$}

Dr Anne L.

Swinbourne ${ }^{1}$

1. James Cook University, Townsville, Queensland.

\section{SUBMITTED}

23 March 2021

\section{ACCEPTED}

26 July 2021

\section{DOI}

www.doi.org/10.47389/36.4.75

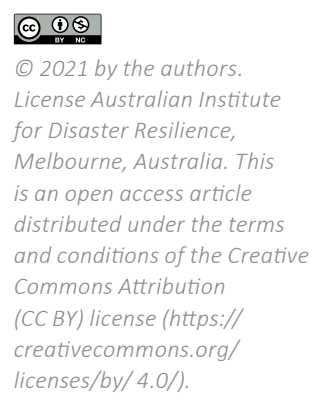

\section{Introduction}

Cyclones occur frequently in the northern parts of Australia with approximately 10 cyclones forming in the region every year and about 6 of those making landfall (Geoscience Australia 2020). Cyclones can significantly impact on the coastline bringing widespread destruction and causing economic loss to industry and infrastructure (Gurtner \& Vachette 2017, Shultz et al. 2005). Residents living in these regions are generally knowledgeable about potential consequences from a cyclone, they have an awareness of what to do to plan for such events and an understanding of how to remain safe (Ramirez et al. 2013). However, despite residents appearing to have a good understanding of the dangers from the wind aspect of a cyclone, many may be less aware of the potential threats from water damage from storm surges.

Anderson-Berry and co-authors (2002) surveyed residents in 2 urban centres in northern Australia and only 22\% of the 915 respondents correctly understood what a storm surge was. When participants were asked what they would do in the case of a storm surge, $75 \%$ of those respondents stated that they had no plan, or they did not answer the question. The research showed a disconnection between understanding the causeand-effect relationship between a cyclone and a storm surge. These inaccurate perceptions about what a storm surge is and how one forms could be attributed to the infrequency of surge occurrence (Morrow et al. 2015). Storm surges have not occurred frequently in populous towns in northern Australia and, therefore, a large proportion of the region's population has not directly experienced such an event and possibly underestimate the dangers that a surge can bring.

Previous experience with an event is generally assumed to result in an individual being more likely to accurately perceive potential risks from similar extreme events (Wachinger et al. 2013). However, the type of experience can influence an individual's evaluation of possible future events. According to Wachinger and colleagues (2013), direct experience can increase perceptions of threat, especially if the consequences were severe. Indirect experience, such as family or friends being directly affected or hearing about an event via the media, can raise awareness of the consequences of extreme events but arguably may not have the effect of direct experience. Conversely, individuals who experienced an event but did not experience danger or damage may underestimate

\section{Abstract}

Storm surges have the potential to bring widespread damage to the north Australian coastline. The dangers from the wind aspect of cyclones are well understood, however, it is unclear if the same can be said about the potential dangers from accompanying storm surges. This study explored the differences between how cyclones and storm surges are perceived by people who are vulnerable to such events. It is important to consider these aspects given that storm surges have not occurred frequently in the past but may happen more often in the future. The sample consisted of 231 undergraduate students studying psychology subjects at James Cook University in Townsville in north Queensland. Participants were asked to record their experience with cyclones and storm surges, their understanding of official warnings used when these events are imminent and a self-assessment of their ability to plan and prepared for these events. Perceptions of severity, possible negative consequences, likelihood and preparedness for both events were also obtained. The results demonstrated that participants living in this region are not as familiar with the particulars of storms surges as they are with cyclones. This study suggests that further research is needed to understand how experience can both facilitate and impede perception of risk, so that risk communication can be best structured for people who do not perceive themselves as being vulnerable. 
the likelihood and consequences of future events (Keller et al. 2006). Perceptions of risk may lessen, and the individual may have a false sense of security regarding the occurrence and consequences of an event and hold misperceptions about their ability to cope (Keller et al. 2006).

The relationship between accurately perceiving a threatening situation and deciding to act in a protective manner has been widely researched (Bubeck et al. 2012). Several theoretical frameworks have examined the factors that predict whether someone is likely to follow recommended guidelines to remain safe (Ejeta et al. 2015). In particular, the Protection Motivation Theory highlights that it is not just the appraisal of threat that predicts how someone intends to behave but rather how they perceive their ability to mitigate or deal with the consequences of threat that elicits adaptive responding (Floyd et al. 2000). Such assessments of ability are referred to as 'perceived efficacy'. In the context of storm surges, the picture is somewhat complicated as it is unclear if surges are perceived as threatening or if the consequences from such events are recognised as potentially dangerous. While increasing perception of threat is an important factor in assisting individuals to understand potential danger from a storm surge, research suggests that this needs to be done in conjunction with communication about effective means to avoid dangerous outcomes (Bubeck et al. 2018).

In order to increase perceptions of threat and efficacy, research is needed to understand how storm surges are perceived in a population that is familiar with the particulars of cyclones but does not have a lot of experience with storm surges. This study explores the differences between how cyclones and storm surges are perceived and seeks to understand how the particulars of storm surges are comprehended in such a population. It is hypothesised that experience with a cyclone or a storm surge will be reflected in a higher level of understanding of the official warning systems used and greater knowledge about how to plan and prepare for that event and will also increase perceptions of the threat variables. Furthermore, it is hypothesised that storm surges will not be perceived as threatening compared to cyclones and the consequences from surges may not be recognised as potentially dangerous.

\section{Method}

\section{Participants}

Participants were recruited as a convenience sample from James Cook University who were studying first or second year psychology subjects. The data used for this study is part of a larger research project that assessed perceptions of other extreme events. Respondents were asked to report their age, gender and postcode of residential address. Given that this study focused on the perceptions about storm surges by individuals living in north Queensland, respondents who indicated that they were from an overseas campus were excluded $(n=212)$. The final sample size consisted of 231 participants ( $68 \%$ female), with an average age of 23.6 years ( $S D=8.55)$.

Ethical approval was obtained through the James Cook University Human Research Ethics Committee (\#H7911).

\section{Measures}

Experience was measured by asking participants if they had direct and/or indirect experience of a cyclone and storm surge. Direct experience was ascertained by asking the participants if they had been personally affected, if they had evacuated from their home or if they had lost items as a direct result of each type of event. Indirect experience was measured by asking participants if the town or city where they lived or if family and friends had been directly affected by a cyclone and/or storm surge. Survey questions covered:

- Own perceptions of understanding of official warnings - participants were asked if they knew about the official warning systems used when a cyclone is approaching or a storm surge is imminent (Yes/No).

- Assessment of ability to plan and prepare - participants were asked to indicate if they were familiar with recommended guidelines for planning and preparing for a cyclone and for a storm surge (Yes/No).

- Perceptions of severity, consequences, likelihood and preparedness - where 'severity' encompassed the entire timeline of the event and assessment of preparedness and 'consequences' dealt solely with the post-event effects. A 5-point Likert scale ranging from 1 (not at all) to 5 (extremely) was used to ascertain the perceptions of the following aspects of cyclones and storm surges:
potential severity
likelihood of one occurring in the next 5 years
magnitude of possible consequences
ability to be prepared for each event.

\section{Procedure}

The survey was made available to university students via Sona Systems website. ${ }^{1}$ The survey was available for 12 months between September 2019 and September 2020. No cyclones or storm surges directly impacted on the region during this time. The survey took approximately 15 minutes to complete. Informed consent was obtained from all participants.

After answering the demographic questions, respondents were presented with a definition of a cyclone and of a storm surge, as:

- cyclone - a low-pressure system that forms over warm tropical waters and has gale-force winds near the centre. The gale-force winds can extend hundreds of kilometres from the cyclone centre. If the sustained winds around the centre reach $118 \mathrm{~km} / \mathrm{hr}$ (gusts in excess of $165 \mathrm{~km} / \mathrm{hr}$ ) then the system is classified as severe (Bureau of Meteorology 2018a)

- storm surge - a raised dome of water about 60 to $80 \mathrm{~km}$ across and typically about 2 to 5 metres higher than the normal tide level. If the surge occurs at the same time as a high tide, then the area inundated can be quite extensive, particularly along low-lying coastlines (Bureau of Meteorology 2018b).

1. Sona Systems is an online research platform used by universities to recruit research participants. 


\section{Results}

Table 1 shows that the majority of respondents reported having experience, understanding of warnings and had plans and preparations in place for cyclones. When considering storm surges, the corresponding proportions were all around one-third of the sample. The exception was indirect experience of storm surges, which was endorsed by around half the sample.

Table 2 shows how 'experience' was related to an understanding of warnings and a preparedness for each type of event. Chi-square tests of association showed that there was a significant association between direct experience of cyclones and understanding of warnings, $\chi^{2}(1, n=231)=11.89, p=0.001$, and direct experience and planning and preparing, $\chi^{2}(1, n=231)=16.45, p<0.001$. Of respondents who stated they were aware of the warning systems used, the majority were also those who had experienced a cyclone. This pattern was repeated when considering those who reported having a plan and being prepared for a cyclone.

An association was also seen for storm surges between direct experience and understanding of warnings, $\chi^{2}(1, n=231)=22.33$, $p<0.001$ and direct experience and planning and preparing $\chi^{2}(1, n=231)=34.20, p<0.001$. However, the pattern was opposite to that observed for cyclones. Over half respondents indicated that they did not have direct experience of a storm surge and were not aware of warning systems for storm surges. A similar proportion reported not having indirect experience nor having a plan/being prepared for the advent of such an event.

A further Chi-square analysis was conducted to explore the relationship between indirect experience and understanding of official warning systems in place for cyclones and storm surges, as suggested by the literature (see Table 3 ). No significant association was seen in the case of cyclones, $\chi^{2}(1, n=231)=1.56, p=0.0212$, but one was found for storm surges, $\chi^{2}(1, n=231)=24.25, p<0.001$. Participants who had no indirect experience with storm surges also tended to report not being aware of the warning systems associated with such an event.

Pearson's product-moment correlations were computed to examine the relationships between age and perceptions of severity, likelihood, possible consequences and ability to plan and prepare for cyclones and for storm surges, and the relationships between the perception variables. Tables 4 and 5 show no significant relationships were detected between age and the

Table 1: Percentage of participants responding 'yes' in each category, for each extreme event.

\begin{tabular}{|c|c|c|c|c|}
\hline \multirow[t]{2}{*}{ Categories } & \multicolumn{2}{|c|}{ Cyclones } & \multicolumn{2}{|c|}{ Storm surges } \\
\hline & N & $\%$ & N & $\%$ \\
\hline Direct experience & 181 & 78.4 & 71 & 30.7 \\
\hline Indirect experience & 193 & 83.5 & 109 & 48.2 \\
\hline Understanding of warnings & 187 & 81.0 & 79 & 34.2 \\
\hline Plan and prepare & 204 & 88.3 & 77 & 33.3 \\
\hline All categories & 136 & 58.9 & 30 & 13.0 \\
\hline
\end{tabular}

Table 2: Crosstabulations for direct experience with cyclones and storm surges.

\section{Understanding of warnings cyclone}

Yes No

\begin{tabular}{|c|c|c|c|}
\hline \multirow{3}{*}{ Direct experience cyclone } & & & \\
\hline & Yes & $67.1 \%$ & $11.3 \%$ \\
\hline & No & $13.9 \%$ & $7.8 \%$ \\
\hline \multicolumn{4}{|c|}{ Planning and preparing for cyclone } \\
\hline & & Yes & No \\
\hline \multirow[t]{4}{*}{ Direct experience cyclone } & Yes & $72.7 \%$ & $5.6 \%$ \\
\hline & No & $15.6 \%$ & $6.1 \%$ \\
\hline & & \multicolumn{2}{|c|}{ Understanding of warnings storm surge } \\
\hline & & Yes & No \\
\hline \multirow[t]{2}{*}{ Direct experience storm surge } & Yes & $17.3 \%$ & $13.4 \%$ \\
\hline & No & $16.9 \%$ & $52.4 \%$ \\
\hline \multicolumn{4}{|c|}{ Planning and preparing for storm surge } \\
\hline & & Yes & No \\
\hline \multirow[t]{2}{*}{ Direct experience storm surge } & Yes & $18.6 \%$ & $12.1 \%$ \\
\hline & No & $14.7 \%$ & $54.5 \%$ \\
\hline
\end{tabular}


Understanding of warnings cyclone

\begin{tabular}{l|cc}
\multicolumn{2}{|c}{} & \multicolumn{2}{c}{ Understanding of warnings cyclone } \\
\hline \multirow{2}{*}{ Indirect experience cyclone } & Yes & $68.8 \%$ \\
\cline { 2 - 3 } & No & $12.1 \%$ \\
\hline Indirect experience Storm Surge & & Understanding of warnings storm surge \\
\cline { 2 - 3 } & Nes & $23.8 \%$ \\
\cline { 2 - 3 } & No & $10.4 \%$ \\
\hline
\end{tabular}

perception variables for either cyclones or storm surges (all $p>0.05$ ). For cyclones, significant positive associations were seen between all other variables (Table 4). The correlation coefficients for the perception variables for storm surges were only significant between the severity and consequences variables and the likelihood and preparedness variables (Table 5).

A point-biserial correlation was run to determine the relationship between gender and perceptions of the severity, likelihood, possible consequences and ability to plan and prepare for cyclones and storm surges. It appeared that females in the sample were more likely than males to report higher perceptions of the severity of cyclones $(r(p b)=0.151, p=0.023)$ (Table 4). Females also tended to perceive their ability to plan and prepare for storm surges as significantly lower than males $(r(p b)=0.178, p=0.007$ ) (Table 5). All other correlations between gender and the listed variables, for both cyclones and storm surges, were not significantly different to zero (all $p s>0.05$ ).

Paired sample t-tests were conducted to see if participant perceptions about the severity, likelihood, consequences and ability to plan and prepare, differed between cyclones and storm surges. The mean rating for each variable and for each event is shown in Table 6. Cyclones were perceived as significantly more severe, more likely to occur, result in more severe consequences and respondents rated themselves as better prepared, compared to storm surges.

Independent t-tests were run to examine if direct experience with each event impacted on how participants perceived the severity, likelihood, possible consequences and ability to plan and prepare for cyclones and storm surges. For both cyclones and storm surges, shown in Table 7 and Table 8, direct experience with the event did not affect how participants rated the severity or how they perceived potential consequences that could occur (all $p>0.05$ ). Respondents with direct cyclone experience rated the likelihood of a cyclone in the next 5 years as significantly higher than those with no direct experience. Those with direct experience also rated their ability to plan and prepare for a cyclone higher than those with no such experience. This pattern was seen in those with direct experience with a storm surge and respondents with direct experience rated the likelihood and their level of preparedness higher than those with no direct experience.

\section{Discussion}

The focus of this study was to examine how storm surges were perceived in a population that is vulnerable to such events. The study first sought to ascertain how familiar participants were with cyclones and with storm surges. Cyclones occur frequently in this region and the results supported that participants were more familiar with cyclones than they were with storm surges. It was not surprising that respondents recorded a greater level of experience with cyclones (78\%) compared to storm surges (31\%), higher levels of understanding of official warning systems used for cyclones (81\%) compared to storm surges (34\%) and greater understanding of how to plan and prepare for wind events (88\%) rather than storm surges (33\%). Despite the differences in the samples used in the study (defined subgroup) and the sample used in the Anderson-Berry and co-authors (2002) survey (systematic household survey), the results of the current study are in line with the earlier research.

\section{Direct experience}

This study explored the role of directly experiencing a cyclone or storm surge on understanding of warning systems and knowledge of what to do to plan and prepare for the event. As suggested by Wachinger and co-authors (2013), experiencing an event may directly increase an awareness of the dangers that may occur and the necessity to take protective action. The results supported the hypothesis that direct experience with either a cyclone or storm surge would be associated with having a better understanding of the official warning systems used and knowing how to plan and prepare for that event.

Despite this link, direct experience was not shown to effect how participants perceived the severity or potential consequences that could occur from a cyclone or from a storm surge. This appears to be understandable for storm surges, as these events have not occurred frequently and it could be expected that individuals would underestimate their perception of risk for these events. However, it was surprising that direct experience with a cyclone did not increase perception of the threat variables. It could be that the experience participants had was not serious enough to elicit a sense of danger about the magnitude of consequences that could occur. It might also be that participants underestimated the intensity of this category of cyclone. There is evidence for such an underestimation of wind speed and intensity in the literature. Scovell and co-authors (2020) asked residents of the region from which the current sample was recruited, to retrospectively estimate the speed of Severe Tropical Cyclone Yasi in their area. All respondents had experienced the fringe effects of the cyclone but none lived in the direct path of the cyclone. Scovell and coauthors (2020) reported that $70 \%$ of the sample overestimated 
Table 4: Correlations of age, gender and perception variables for cyclones.

\begin{tabular}{lrrrrr} 
Variables & $\mathbf{1 .}$ & $\mathbf{2 .}$ & $\mathbf{3 .}$ & $\mathbf{4 .}$ & $\mathbf{5 .}$ \\
\hline 1. Age & - & & & & \\
\hline 2. Gender & 0.011 & - & & & \\
\hline 3. Severity & 0.060 & $0.151^{*}$ & & & \\
\hline 4. Likelihood & 0.018 & 0.068 & $0.344^{* *}$ & - & \\
\hline 5. Consequences & 0.102 & -0.018 & $0.497^{* *}$ & $0.194^{* *}$ & - \\
\hline 6. Prepared & 0.115 & 0.064 & $0.228^{* *}$ & $0.374^{* *}$ & $0.181^{* *}$ \\
\hline
\end{tabular}

${ }^{*} p<0.05 .{ }^{*} p<0.01$.

Table 5: Correlations of age, gender and perception variables for storm surges.

\begin{tabular}{|c|c|c|c|c|c|c|}
\hline Variables & 1. & 2. & 3. & 4. & 5. & 6. \\
\hline 1. Age & - & & & & & \\
\hline 2. Gender & 0.011 & - & & & & \\
\hline 3. Severity & 0.005 & 0.022 & - & & & \\
\hline 4. Likelihood & 0.021 & -0.056 & 0.036 & - & & \\
\hline 5. Consequences & -0.037 & 0.018 & $0.588^{* *}$ & 0.119 & - & \\
\hline 6. Prepared & 0.089 & $-0.178 * *$ & 0.080 & $0.299 * *$ & 0.086 & - \\
\hline
\end{tabular}

Table 6: Results from paired t-test comparing cyclones and storm surges.

\begin{tabular}{lccccccc}
\hline Type & \multicolumn{2}{c}{ Cyclones } & \multicolumn{2}{c}{ Storm Surges } & $\boldsymbol{t}$ & $\boldsymbol{p}$ \\
& M & SD & M & SD & & \\
Severity & 3.42 & 0.880 & 2.97 & 0.944 & 6.675 & 0.000 \\
\hline Likelihood & 4.24 & 0.852 & 3.06 & 1.080 & 14.193 & 0.000 \\
\hline Consequences & 3.84 & 0.852 & 3.39 & 0.852 & 7.683 & 0.000 \\
\hline Preparedness & 3.73 & 0.863 & 2.70 & 1.140 & 13.464 & 0.000 \\
\hline
\end{tabular}

Table 7: Direct experience with a cyclone.

\begin{tabular}{|c|c|c|c|c|c|c|}
\hline \multirow[t]{2}{*}{ Type } & \multicolumn{2}{|c|}{$\begin{array}{c}\text { Yes } \\
n=181\end{array}$} & \multicolumn{2}{|c|}{$\begin{array}{c}\text { No } \\
n=50\end{array}$} & \multirow[t]{2}{*}{$t$} & \multirow[t]{2}{*}{$p$} \\
\hline & $M$ & SD & M & SD & & \\
\hline Severity & 3.43 & 0.883 & 3.36 & 0.875 & 0.504 & 0.615 \\
\hline Likelihood & 4.33 & 0.774 & 3.96 & 1.049 & 2.726 & 0.007 \\
\hline Consequences & 3.86 & 0.761 & 3.76 & 0.822 & 0.779 & 0.437 \\
\hline Preparedness & 3.86 & 0.790 & 3.28 & 0.970 & 4.338 & 0.000 \\
\hline
\end{tabular}

Table 8: Direct experience with a storm surge.

\begin{tabular}{|c|c|c|c|c|c|c|}
\hline \multirow[t]{2}{*}{ Type } & \multicolumn{2}{|c|}{$\begin{array}{c}\text { Yes } \\
\mathbf{n}=71\end{array}$} & \multicolumn{2}{|c|}{$\begin{array}{c}\text { No } \\
\mathrm{n}=160\end{array}$} & \multirow[t]{2}{*}{$t$} & \multirow[t]{2}{*}{$p$} \\
\hline & $M$ & SD & M & SD & & \\
\hline Severity & 3.01 & 0.933 & 2.95 & 0.950 & 0.475 & 0.635 \\
\hline Likelihood & 3.65 & 0.927 & 2.81 & 1.043 & 5.849 & 0.000 \\
\hline Consequences & 3.39 & 0.836 & 3.39 & 0.861 & 0.056 & 0.955 \\
\hline Preparedness & 3.17 & 0.926 & 2.49 & 1.165 & 4.354 & 0.000 \\
\hline
\end{tabular}


the wind speed in their area by at least one cyclone category level. Given that the locations sampled in that study (Scovell et al. 2020) and that participants did not experience any extensive damage to housing stock and other property from that cyclone, it was also not surprising that the respondents also underestimated the consequences of future cyclones.

Direct experience with a cyclone or with a storm surge in this study was positively associated with the intention to plan and prepare for an event. This suggests that participants had confidence to take action to avoid harm when faced with these events. However, given that experience did not increase perceptions of threat, it could be that participants had overconfidence in their ability to plan and prepare, as they underestimated the potential threat from the situation. Figure 1 shows the extent of inundation and evacuation zones in Townsville.

\section{Indirect experience}

Indirect experience has been suggested to increase knowledge about an event, through raising awareness through media outlets or because family or friends had been impacted (Wachinger et al. 2013). The study examined if indirect experience increased the likelihood of participants being aware of the official systems used to convey the risk from an approaching cyclone or storm surge. While a large percentage of the sample had indirect experience with a cyclone (84\%) and a storm surge (49\%), this variable was only shown to be associated with participants' understandings of warning systems in the context of storm surges. However, this was only reflected for those respondents who did not have indirect experience and were not aware of official warnings for storm surges. Indirect experience was therefore not shown to impact on this variable in a meaningful way. For cyclones, the overall awareness was already high, given that $78 \%$ of participants recorded having direct experience, and so indirect experience alone did not influence on how many participants indicated that they were aware of official risk communication.

While indirect experience has been shown to increase knowledge about an event (Wachinger et al. 2013), this was not supported in this study, raising questions about possible ambiguity on this variable. It could be that indirect experience was too broad a category, encompassing a wide range of experience or anecdotal recollections rather than specific events that could contribute to an increase in knowledge.

\section{Age and gender demographics}

The study did not find any significant relationship between the age and perceptions of the severity, likelihood, possible consequences and ability to plan and prepare for cyclones and for storm surges. While females perceived cyclones to be more severe than males and reported being less able to plan and prepare for a storm surge compared to males, these were very weak relationships. Therefore, it can be concluded that gender did not appear to have a meaningful impact on the perception variables in this sample.

\section{Comparison between cyclones and storm surges}

Finally, the study examined if there were differences between how participants perceived cyclones and storm surges. Cyclones were perceived as more severe, more likely to occur, result in more consequences and more able to be prepared for than storm surges. While this result was not surprising, given that more

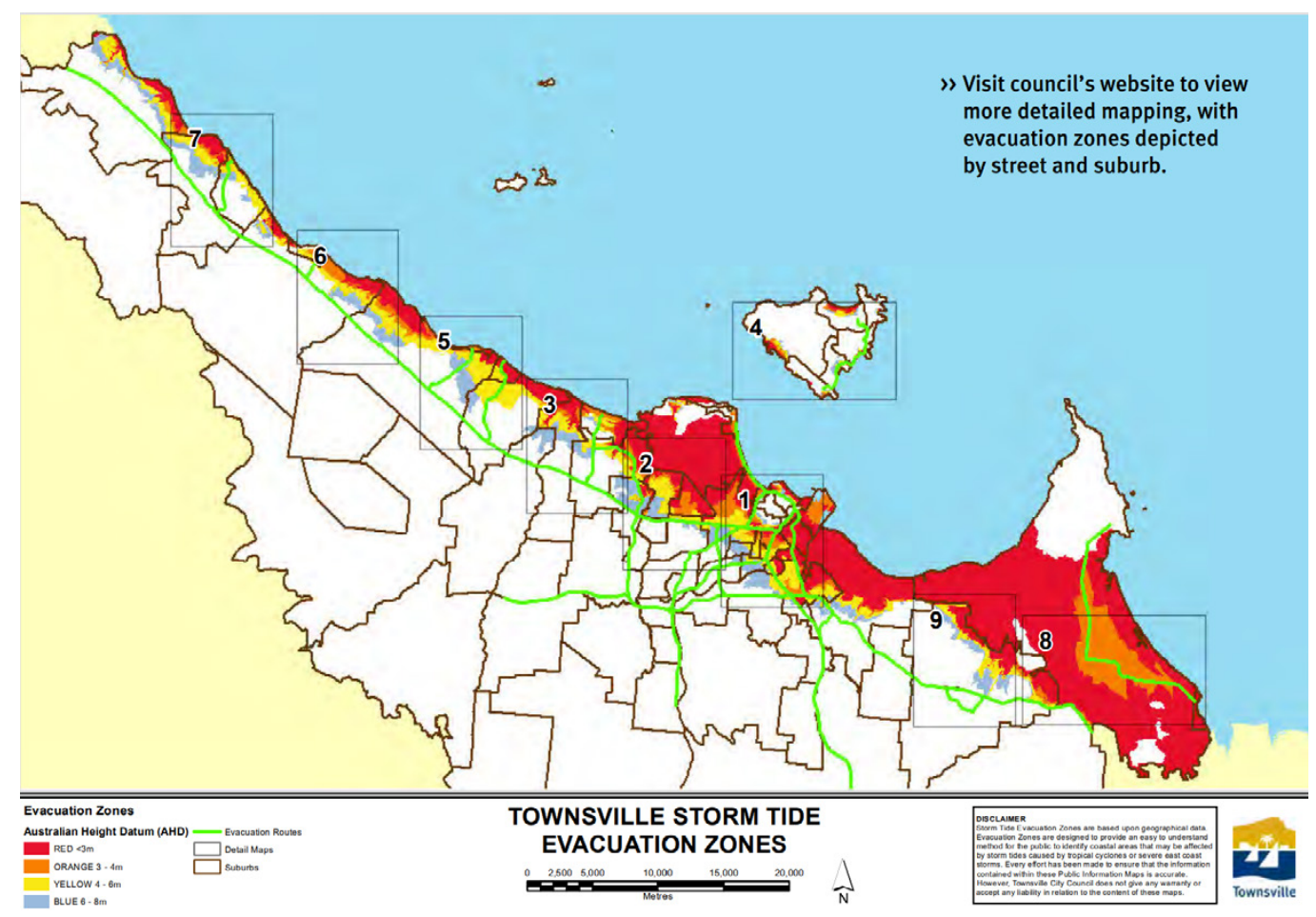

Figure 1: Map of Townsville, Queensland, showing storm surge inundation and evacuation zones.

Source: Townsville Storm Tide Evacuation Guide, at www.townsville.qld.gov.au/__data/assets/pdf_file/0021/6735/TCC_Evacuation-Guide.pdf. 
participants had experienced a cyclone, it highlights that the threat from a storm surge appears to be underestimated. In order to increase awareness of how to remain safe during a storm surge, it is imperative to increase perceptions of the danger a storm surge can bring. Understanding how storm surges are perceived can inform further research to contribute to improving community awareness and preparedness behaviours.

Several limitations were identified in the study. First, the use of a student convenience sample may not be representative of the general population. The aim of this study was to ascertain how storm surges are perceived in relation to cyclones and to inform further research in a population at risk from these events but with differential experience of each. Therefore, this limitation should not affect the interpretation of the results within the context of an early tertiary educated, young adult sample. The results also provide evidence for the likely usefulness of further investigations with a broader sample. Second, it is acknowledged that the descriptive approach to asking participants about their knowledge about cyclones and storm surges may be biased and not reflect accurate, objectively gathered information. This study sought to establish a baseline of perceptions, as it is important to understand what individuals think they know in order to assess the foundations for intentions and behaviour. Future research could explore how participant subjective interpretations reflect objective information.

\section{Conclusion}

The dangers from cyclonic winds are widely known in north Queensland. However, this study demonstrated that some residents living in this region may not be as familiar with the particulars of storm surges. While storm surges have not occurred frequently in this region and respondents predictably had limited experience with these events, the study highlighted that the multifaceted nature of experience warrants further exploration. Future research should focus on how experience can both facilitate and impede risk perception, to further understand how to target risk communication, in particular for individuals who do not perceive themselves as vulnerable.

\section{References}

Anderson-Berry L, King D \& Crane G 2002, Assessment of the Effectiveness of Various Methods of Delivery of Public Awareness Information on Tropical Cyclones to the Queensland Coastal Communities. Emergency Management Australia. At: www.jcu. edu.au/_data/assets/pdf_file/0017/123425/jcutst_056225. pdf/_noproxycache.

Bubeck P, Botzen WJW \& Aerts JCJH 2012, A Review of Risk Perceptions and Other Factors that Influence Flood Mitigation Behavior. Risk analysis, vol. 32, pp.1481-95.

Bubeck P, Botzen WJW, Laudan J, Aerts JCJH \& Thieken AH 2018, Insights into Flood-Coping Appraisals of Protection Motivation Theory: Empirical Evidence from Germany and France: Insights into Flood-Coping Appraisals of Protection Motivation Theory. Risk analysis, vol. 38, pp.1239-57.

Bureau of Meteorology 2018a, About tropical cyclones. At: www. bom.gov.au/cyclone/about/.
Bureau of Meteorology 2018b, Storm surge preparedness and safety: Depiction of normal high tide and cyclone storm surge. At: www.bom.gov.au/cyclone/about/stormsurge.shtml.

Ejeta LT, Ardalan A \& Paton D 2015, Application of behavioral theories to disaster and emergency health preparedness: A systematic review. PLOS Currents Disasters. 2015 July 1. Edition 1. doi: 10.1371/currents.dis.31a8995ced321301466db400f1357829

Floyd DL, Prentice-Dunn S \& Rogers RW 2000, A Meta-Analysis of Research on Protection Motivation Theory. Journal of Applied Social Psychology, vol. 30, pp. 407-429.

Geoscience Australia 2020, Severe Wind. At: www.ga.gov.au/ scientific-topics/community-safety/severe-wind\#: :text=On\%20 average $\% 2$ C20about $\% 2010 \% 20$ cyclones,of\%20these $\% 20$ cross\%20the\%20coast.

Gurtner Y \& Vachette A 2017, Community post impact assessment - rapid appraisal: Tropical Cyclone Debbie, Whitsunday Coast, QLD, Australia 5-8 April 2017. James Cook University.

Keller C, Siegrist M \& Gutscher H 2006, The Role of the Affect and Availability Heuristics in Risk Communication. Risk Analysis, vol. 26, pp.631-639.

Morrow BH, Lazo JK, Rhome J \& Feyen J 2015, Improving storm surge risk communication: Stakeholder perspectives. Bulletin of the American Meteorological Society, vol. 96, pp.35-48.

Ramirez S, Antrobus E \& Williamson H 2013, Living in Queensland: Preparing for and communicating in disasters and emergencies. Australian Journal of Communication, vol. 40, pp.1-21.

Scovell M, McShane C, Swinbourne A \& Smith D 2020, How fringe cyclone experience affects predictions of damage severity. Disaster Prevention and Management, vol. 30, no. 2, pp.240-254. doi:10.1108/DPM-07-2019-0228

Shultz JM, Russell J \& Espinel Z 2005, Epidemiology of tropical cyclones: The dynamics of disaster, disease, and development. Epidemiologic reviews, vol. 27, pp.1-35.

Wachinger G, Renn O, Begg C \& Kuhlicke C 2013, The Risk Perception Paradox-Implications for Governance and Communication of Natural Hazards. Risk analysis, vol. 33, pp.1049-65.

\section{About the authors}

Kristy Livock is a PhD candidate at James Cook University. Her research focuses on the psychological aspects of risk perception and decision-making in the context of natural hazards, in particular storm surges.

Dr Anne L. Swinbourne is a senior lecturer in Psychology at James Cook University. Her research interests include the use of information and narrative technologies to effect attitude and behaviour change. Her research focuses on shaping and delivering information to improve attention to it and shape behavioural responses. 